\title{
A aceleração das contrarreformas no SUS e a transferência de valor ao setor privado pelo governo Temer
}

\author{
The acceleration of counter-reforms in the Unified Health System (SUS) and the transfer \\ of value to the private sector by the Temer government
}

\section{Adriana Ilha da SILVA*}

$\mathrm{O}$ texto As contrarreformas na política de saúde do governo Temer, da professora Maria Inês Bravo junto com a Elaine Pelaez e Wladimir Pinheiro (2018), elenca aspectos e informações importantes para a análise do papel do Estado na dinâmica atual do Capitalismo. Em especial, ao seu desenvolvimento histórico-concreto ao apontar as disputas entre os projetos antagônicos de saúde, os grupos de interesses e as possíveis estratégias de mobilização e de resistências à essas contrarreformas.

O artigo apresenta historicamente a origem e a natureza dos projetos distintos e contraditórios na sociedade brasileira desde antes da Constituição Brasileira de 1988 (BRASIL, 1988), e como as correlações de forças entre esses grupos se acirraram a partir da década de 1990, com a implementação do projeto neoliberal no Brasil, e com a cultura da política da crise. Neste sentido, os autores nos levam a refletir sobre a verdadeira natureza do Estado capitalista na contemporaneidade e suas implicações às ações no campo da saúde.

Em nível de abstração, acreditamos que a natureza do Estado ${ }^{1}$ capitalista no exercício do seu poder de controlar, gerir, dirigir e comandar em suas diversas dimensões (econômica, política, jurídica, ideológica e policial/militar) “[...] busca incessante pela produção e pela apropriação diferenciada da riqueza real excedente" (NAKATANI; GOMES, 2014, p. 72). Ou seja, a sua ação concreta está voltada para solucionar as crises inerentes ao capital, criando novas estratégias e fontes para a sua acumulação. Para alcançar tal intento, a ação estatal interferirá no conjunto da sociedade, para reorganizar tanto as condições necessárias à produção e relações de exploração quanto para a própria reprodução da força de trabalho. Logo, a mesma ação do Estado pode apresentar duas funções: o da acumulação e da legitimação. A “[...] função/acumulação é determinada fundamentalmente pelas restrições à acumulação, enquanto a função/legitimação o é pela reprodução social" (NAKATANI, 1987, p. 56).

\footnotetext{
* Assistente Social. Doutora em Política Social (UFES). Professora Adjunta do Departamento de Serviço Social, Professora colaboradora do Programa de Pós-Graduação em Saúde Coletiva, coordenadora do Labic, na Universidade Federal do Espírito Santo (Ufes, Vitória (ES), Brasil). Av. Fernando Ferrari, 514, Goiabeiras, Vitória (ES), CEP. 29075-073. E-mail: <adrianailhaufes@gmail.com>. ORC ID: <http://orcid.org/oooo0001-8698-5768>.

1 "A forma Estado é deduzida do ciclo do capital; a sucessão de categoria M - V - D - C (Mercadoria - Valor - Dinheiro - Capital) o que implica o Estado. Este, enquanto abstração, apresenta a sua forma 'ao lado e acima do capital'. E esta forma 'se efetiva na realidade da luta de classes sob a forma do regime político [...]. Esta é a forma do Estado” (NAKATANI, 1987, p. 54-55).
} 
No âmbito do desenvolvimento histórico da ação estatal ou da interferência governamental na área da saúde, percebe-se duas tendências: uma sob perspectiva da seguridade social e a outra visando a racionalização dos serviços com o objetivo de elevar a sua produtividade. A primeira é compreendida a partir do princípio da universalidade, da participação estatal na organização e provisão dos serviços de saúde. Ou seja, do significado de direito à saúde a ser incorporado pelo Estado como sua responsabilidade social, como expressão dos interesses coletivos na concepção de bem-estar social. Essa abordagem apresenta sua base explicativa e histórica no desenvolvimento do conceito de cidadania, de direitos sociais concebidos numa perspectiva histórica de igualdade social, pautada no "[...] equilíbrio entre justiça social e a liberdade de mercado no sistema capitalista" (DONNANGELO, 1973, p. 4). Já a racionalização é entendida como tarefas técnicas de planejamento e de coordenação dos serviços de saúde, apresentando "[...] a necessidade de uma ação centralizada que corrija as distorções no setor, principalmente as que resultam da multiplicidade e sobreposição de recursos" (DONNANGELO, 1973, p. 2). Cabe ressaltar que essas tendências apresentam características particulares e internas a cada país, ou melhor, a cada Estado Nacional.

No Brasil, ao analisar essas particularidades e as funções de acumulação e de legitimação intrínsecos ao papel do Estado, observou-se que a complexidade frente às resoluções das crises do capital aumenta tanto a contradição entre a função acumulação e de legitimação, quanto a intervenção estatal à reprodução da força de trabalho, de maneira a limitá-la cada vez mais. Isto é resultante das novas estratégias de expansão do capital fictício, e, que no campo da assistência à saúde, expande suas ações de maneira a privilegiar o setor privado e filantrópico (SODRÉ; BAHIA; BUSSINGER, 2018).

Mesmo com a aprovação da nova Constituição do Brasil em outubro de 1988 - estabelecendo a saúde como parte da seguridade social (art.194), direito de todos e dever do Estado (art. 196) - não foi suficiente para diminuir a contradição entre a função de acumulação e legitimação do Estado, uma vez que as ações governamentais continuaram a limitar cada vez mais os direitos à reprodução social da força do trabalho, como nesse caso específico à saúde. A própria análise do processo constituinte apresenta os distintos projetos em disputa e antagônicos: os defensores da estatização dos serviços de saúde e os patronos da iniciativa privada. Nessa disputa, foram os partidos que se opuseram à Reforma Sanitária, que "[...] por ironia da história, passaram a ser responsáveis pela implantação do SUS [...]” (ESCOREL; TEIXEIRA, 2012.), no governo Collor (1990-1992).

O Brasil ao privilegiar o desenvolvimento do projeto neoliberal desde a década de 1990, tem a sua radicalidade no mandato de Michel Temer. A intervenção estatal direciona-se para a maior liberdade ao movimento de capitais, inserindo o país na lógica da financeirização. Ou seja, no desenvolvimento exacerbado das formas do capital fictício, especulação nas bolsas de valores e nos mercados de títulos público (CARCANHOLO; NAKATANI, 1999). A consequência disso é o crescimento e a concentração da riqueza de um lado, enquanto do outro há o aumento da miséria, do desemprego, dos ajustes fiscais, e a diminuição com os gastos sociais - o que acentua as contradições entre a função de acumulação e legitimação do Estado. Assim, cada vez mais é necessário limitar a interferência estatal na reprodução social da força de trabalho para solucionar as crises de acumulação do capital.

Argum., Vitória, v. 10, n. 1, p. 51-56, jan./abr. 2018. 
E, nessa conjuntura, a implementação e a efetivação do Sistema Único de Saúde contraria a lógica da acumulação financeira, assim como outras políticas voltadas aos trabalhadores. Sob a orientação do Banco Mundial (BM), os governos capitalistas devem orientar a política de saúde à perspectiva de sua racionalização. Ou seja, implementação de medidas contencionistas por meio de ajustes econômicos e estruturais, privilegiando o setor privado e filantrópico. Mesmo que isso contraponha a sua Constituição Máxima, que no caso brasileiro institui a garantia da universalidade ao acesso à saúde e da responsabilização do Estado, tanto em sua organização e execução, por meio de administração direta (VIANA; MACHADO, 2008).

As ações do governo Temer direcionam-se no sentido de obedecer às orientações do Banco Mundial, ou seja, para a racionalização dos serviços de saúde. Em vista disso, introduz cada vez mais mecanismos de reordenamento institucional, como por exemplo a Emenda Constitucional 95/2016 (BRASIL, 2016a), que congela os gastos com a saúde, acarretando a redução do quadro de pessoal, de equipamentos e criando novos empecilhos para o financiamento do SUS durante 20 anos. Isso porque, a "[...] crise de financiamento, a partir desse ambiente de dominância financeira, foi explicitada pela adoção de uma política macroeconômica restritiva, resultando em tentativas de diminuição dos gastos na saúde" (MENDES; MARQUES, 2009, p. 844). Outro exemplo, e a Portaria no 1.482, de 04 de agosto de 2016 (BRASIL, 2016b), a qual institui um grupo de trabalho composto essencialmente por representantes do Ministério da Saúde, da Agência Nacional de Saúde Suplementar (ANS) e da Confederação Nacional das Empresas de Seguros Gerais, Previdência Privada e Vida, Saúde Suplementar e Capitalização (CNSEG), com o objetivo se construir uma nova modalidade de plano de saúde, denominada como acessível ou popular. Não há no Grupo de Trabalho prevista a participação de usuários, dentre outros atores.

O governo se apoia na cultura da política de crise para justificar suas ações de saúde suplementar, ou seja, a contratação do setor privado: medicina de grupo, cooperativa médica, autogestão, seguradora, hospitais filantrópicos e outras. Parte das empresas privadas de saúde (planos e seguros) expandiram e diversificaram suas atividades, vinculando-se a grandes instituições bancárias, outras abriram suas ações nas bolsas de valores, inserindo-se à lógica da acumulação financeira. Como exemplo, pode-se citar a Qualicorp, empresa de planos de saúde, cujo lucro líquido no quarto trimestre de 2017 foi de $\mathrm{R} \$ 90,4$ milhões, representando um aumento de $15,3 \%$ em seus rendimentos quando comparado ao mesmo período do ano de 2016 (SELMI, 2018). Outro exemplo é do maior acionista da Rede de Hospitais D'OR, que segundo a lista da Revista Forbes (2018), acumulou até o dia 8 de abril de 2018, uma fortuna de US\$ 2,5 bilhões de dólares, cuja fonte dessa riqueza restringe-se a sua rede de hospitais (FORBES, 2018). Assim, a lógica de acumulação financeira criou a tendência à concentração no setor de saúde e mudanças na configuração do mercado de planos e seguros.

A necessidade de maior expansão do setor privado de saúde e a sua preservação caracterizase também pela disputa dos recursos do SUS por meio do regime de complementaridade, através das Organizações Sociais de Saúde. Atualmente, há ${ }_{51}$ Organizações Sociais de Saúde no Brasil, as 10 maiores situam-se nos estados de São Paulo e Rio de Janeiro, totalizando desde 1998, cerca de 226 contratos de gestão e 978 contratos aditivos (BAHIA et al., 2017). 
Assim, tanto as empresas privadas quanto as filantrópicas criam as suas próprias estratégias para sua concorrência no setor da saúde. Trata-se do processo de terceirização e de privatização, os quais permitem a transferência de valor, para o setor privado (TRISTÃO, 2017).

Conclui-se que o governo de Temer não demonstra disposição em aumentar sua participação no gasto com a rede própria de saúde, "[...] nem em definir fontes exclusivas para seus custeios e tampouco em firmar o compromisso com o as políticas sociais universais, investindo em saúde" (MENDES; MARQUES, 2009, p. 849). Como também não pretende que as condições necessárias à acumulação financeira no Brasil preservem uma política econômica que subordine a saúde no país. "A adoção de políticas macroeconômicas restritivas, isto é, de cumprimento às metas de inflação e de ajuste das contas externas, exige sempre superávits primários fiscais altos e tentativas de redução dos gastos públicos sociais" (MENDES; MARQUES, 2009, p. 842).

Assim, na defesa da racionalização dos serviços, com vistas a elevação da sua produtividade, o atual governo, por meio do seu Ministro da Saúde, utiliza como estratégia estatal a transferência de valor ao setor privado e filantrópico e não a garantia da implementação do SUS. Por mais que nossa mobilização, resistência e luta seja na direção da defesa e da ampliação do direito à saúde, necessita-se ter em mente que essa luta terá que ser, principalmente, contra as políticas macroeconômicas, que operacionalizam a política monetária e a política trabalhista, com o objetivo de garantir às leis gerais da acumulação do capital.

\section{REFERÊNCIAS}

BRASIL. Constituição da República Federativa do Brasil. Brasília (DF): Senado Federal, 1988.

BRASIL. Ministério da Saúde. Portaria no 1.482, de 4 de agosto de 2o16. Institui Grupo de Trabalho para discutir projeto de Plano de Saúde Acessível. Brasília (DF), 2016. Disponível em: <http://bvsms.saude.gov.br/bvs/saudelegis/gm/2016/prt1482_04_o8_2016.html>. Acesso em: 9 abr. 2018.

BRASIL. Presidência da República. Emenda Constitucional 95, de 15 de dezembro de 2016. Altera o Ato das Disposições Constitucionais Transitórias, para instituir o Novo Regime Fiscal, e dá outras providências. Brasília (DF), 2016a. Disponível em: <http://www.planalto.gov.br/ccivil_03/constituicao/emendas/emc/emc95.htm>. Acesso em: 9 abr. 2018.

BRASIL. Ministério da Saúde. Portaria no 1.482, de 4 de agosto de 2016. Institui Grupo de Trabalho para discutir projeto de Plano de Saúde Acessível. Brasília (DF), 2016b. Disponível em: <http://bvsms.saude.gov.br/bvs/saudelegis/gm/2016/prt1482_04_o8_2016.html>. Acesso em: 9 abr. 2018.

BAHIA, L. et al. Complexo Econômico Industrial da Saúde (CEIS), inovação e dinâmica capitalista: desafios estruturais para a construção do sistema universal no Brasil. Projeto CNPq. Rio de Janeiro: IESC; UFRJ, 2017. 
CARCANHOLO, R. A.; NAKATANI, P. O capital especulativo parasitário: uma precisão teórica sobre o capital financeiro, característico da globalização. Ensaios FEE, Porto Alegre, v. 20, n. 1, p. 264-304, jun. 1999.

DONNANGELO, M. C. F. Medicina e sociedade: o médico e seu mercado de trabalho. São Paulo: Pioneira, 1973.

ESCOREL, S. História das Políticas de Saúde no Brasil de 1964 a 1990: do golpe militar à reforma sanitária. In: GIOVANELLA, L. et al. (Orgs.). Políticas e Sistemas de Saúde no Brasil. 2. ed. rev. e amp. Rio de Janeiro: Editora FIOCRUZ, 2012. p. 323-363.

ESCOREL, S.; TEIXEIRA, L. A. História das Políticas de Saúde no Brasil de 1822 a 1963: Do império ao desenvolvimentismo populista. In: GIOVANELLA, L. et al. (Orgs.). Políticas e Sistemas de Saúde no Brasil. 2. ed. rev. e amp. Rio de Janeiro: FIOCRUZ, 2012, pp. 279-321.

FORBES. Lista de Bilionários do mundo. Ranking 2018. [S. 1.], 2018. Disponível em: $<$ https://www.forbes.com/billionaires/list/\#version:realtime_search:Jorge\%2oMol>. Acesso em: 9 abr. 2018.

MENDES, A.; MARQUES, R. O financiamento do SUS sob os "ventos" da financeirização. Ciência \& Saúde Coletiva, Rio de Janeiro, v. 14, n. 3, p. 841-850, jun. 2009.

NAKATANI, P.; GOMES, H. A natureza e as contradições da crise capitalista. Políticas Públicas, São Luís, Número Especial, p. 71-83, jul. 2014.

NAKATANI, P. Estado e acumulação do capital: discussão sobre a teoria da derivação. Análise Econômica, Porto Alegre: Faculdades de Ciências Econômicas, v. 5, n. 8, p. 35-64, 1987.

SELMI, P. Lucro da Qualicorp sobe $15,3 \%$ no $4^{\text {o }}$ trimestre de 2017. Valor Econômico, São Paulo, 15 mar. 2018. Disponível em: <http://www.valor.com.br/empresas/5388177/lucro-daqualicorp-sobe-153-no-4-trimestre-de-2017>. Acesso em: 9 abr. 2018.

SODRÉ, F; BAHIA, L; BUSSINGER, E. Organizações sociais: agenda política e os custos para o setor público de saúde. Rio de Janeiro: Hucitec, 2018.

TRISTÃO, E. A terceirização e a acumulação de capital. In: COLÓQUIO INTERNACIONAL MARX E O MARXISMO 2017: De O capital à Revolução de Outubro (1867 - 1917). Anais... Niterói: Sociedade Latino-americana de Economia Política e Pensamento Crítico; Universidade Federal de Fluminense, 21 a 25 de agosto de 2017.

VIANA, A. L. d'A; MACHADO, C. V. Proteção social em saúde: um balanço dos 20 anos do SUS. Physis, Rio de Janeiro, n. 18, p. 645-684, 2008. 


\section{Adriana Ilha da SILVA}

Assistente Social. Doutora em Política Social (UFES). Professora Adjunta do Departamento de Serviço Social, Professora colaboradora do Programa de Pós-Graduação em Saúde Coletiva, Coordenadora do Labic, na Universidade Federal do Espírito Santo (UFES). Integrante do grupo de Estudos do Desenvolvimento sob a linha de pesquisa $O$ Estado na dinâmica atual do Capitalismo e do grupo de Estudos em Trabalho e Saúde (GEMTES/PPGSC). 